\title{
BOOKS
}

\section{Polymerase chain reaction text} PCR in situ Hybridization: Protocols and Applications, by Gerard J Nuovo (1992). Raven Press, Ltd, 1185 Avenue of the Americas, New York, New York 10036, USA. 264 pages

One of the most significant technological advances in molecular biology is the development of the polymerase chain reaction ( $\mathrm{PCR}$ ). This procedure can be used to detect single copy genes or diagnose microbial infections in minute samples, due to the in vitro exponential amplification of specific nucleic acid sequences. The technique has been restricted to amplifying extracted target DNA or RNA sequences, precluding correlations between cytological or histological features and molecular findings. However, by the publication of PCR in situ Hybridization, this limitation is overcome. This text describes in detail a technique that marries surgical pathology and molecular biology, with markedly improved sensitivity over classic in situ hybridization. The infections caused by human papillomavirus and human immunodeficiency virus 1 are used effectively throughout the book to illustrate the application of a variety of molecular techniques, although the author emphasizes that the procedures are broadly applicable to genetically based, as well as other infectious, human diseases.

The author sets out to describe the PCR in situ technique in comprehensible terms for both the surgical pathologist and the molecular biologist. Hence, the first two chapters are extremely basic, focusing on the structure of DNA and defining the 'jargon' associated with molecular biology. In Chapter 3 , the reader is finally introduced to the conventional PCR technique. The procedure, with associated limitations and pitfalls, is outlined very clearly in the text. The description of the effect of various tissue fixatives on the amplifiability of DNA is particularly useful. However, the accompanying figure misses the mark, while filling three pages.
The fundamental problem of nonspecific amplification of DNA is dealt with in Chapter 4 , with the support of excellent illustrations. The key concept of 'hot start' is introduced as a means of improving both the specificity and sensitivity of conventional PCR and is cited in later chapters as essential to the success of in situ PCR.

Chapter 5 describes the classic in situ hybridization procedure. A detailed description of the technique is provided, augmented by photographs depicting the effects of protease treatment and tissue fixation on hybridization signals. Unfortunately, the use of black and white photography to illustrate the appearance of different counterstains and chromagens is counterproduc tive. While a few colour photos are provided, these are sequestered in a later section of the book. The reader must flip back and forth to make comparisons.

The remainder of the text deals with PCR in situ hybridization or in situ PCR. In the later case, labelled nucleotides are incorporated directly into the amplified product, precluding the hybridization step. The author emphasizes that the technique is still under development and as such the methods he describes "are most definitely not the final story". Thus, while the procedure provides insight into the cellular and histological distribution of viral DNA, RNA and human mRNA, the utility of the technique in the routine diagnostic laboratory is questionable.

In summary, the strength of the book lies in the emphasis placed on the use of appropriate controls and in providing excellent instructions and problemsolving algorithms. The author has gone to great lengths to build up gradually the expertise of the reader, such that the novice, as well as the expert molecular biologist, will be undaunted by the technology. For anyone contemplating using PCR in situ hybridization in a research setting, this book is invaluable.

$P$ MCNicol PhD Cadham Provincial Laboratory and The University of Manitoba Winnipeg. Manitoba 


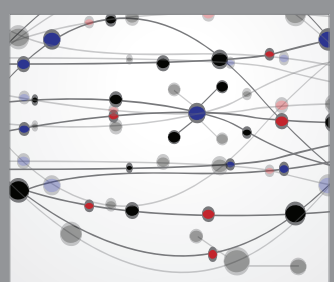

The Scientific World Journal
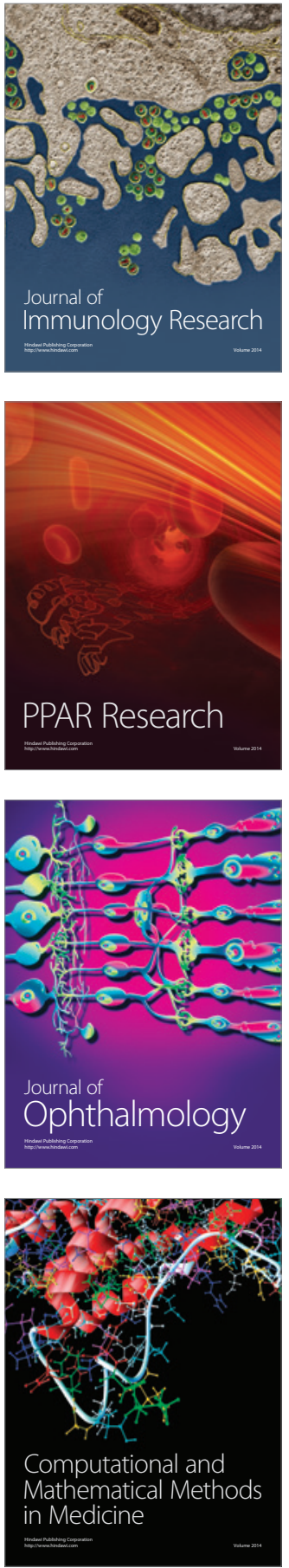

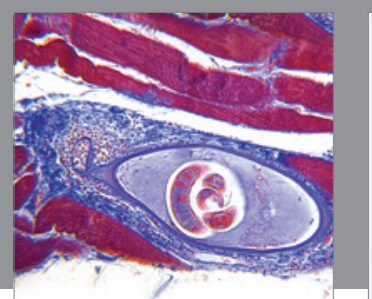

Gastroenterology Research and Practice

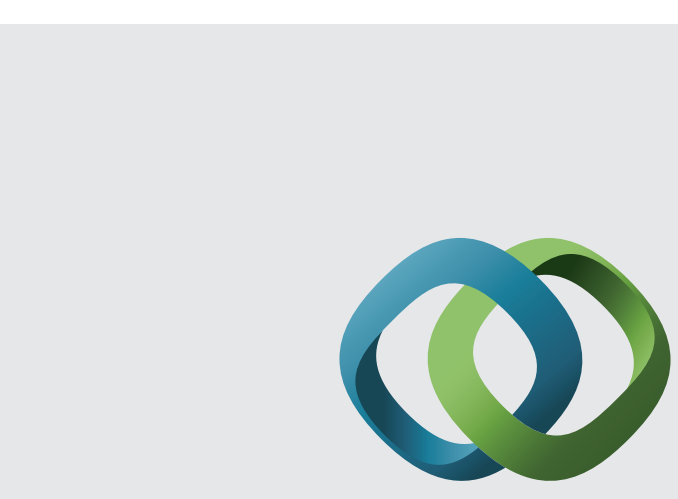

\section{Hindawi}

Submit your manuscripts at

http://www.hindawi.com
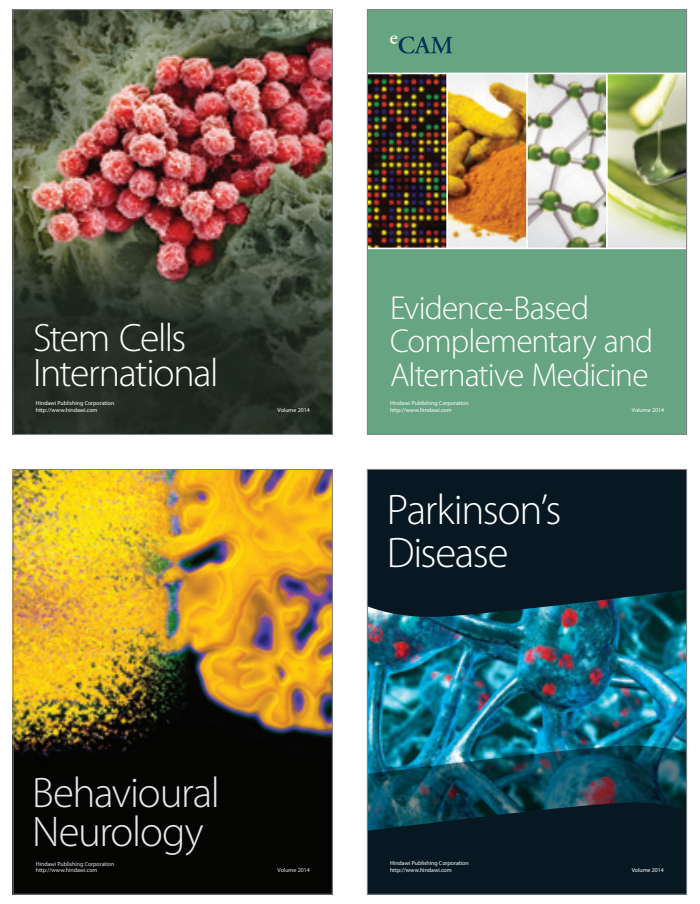
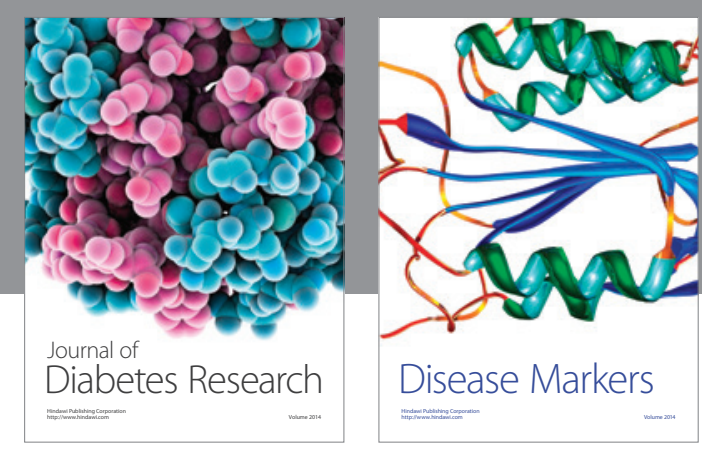

Disease Markers
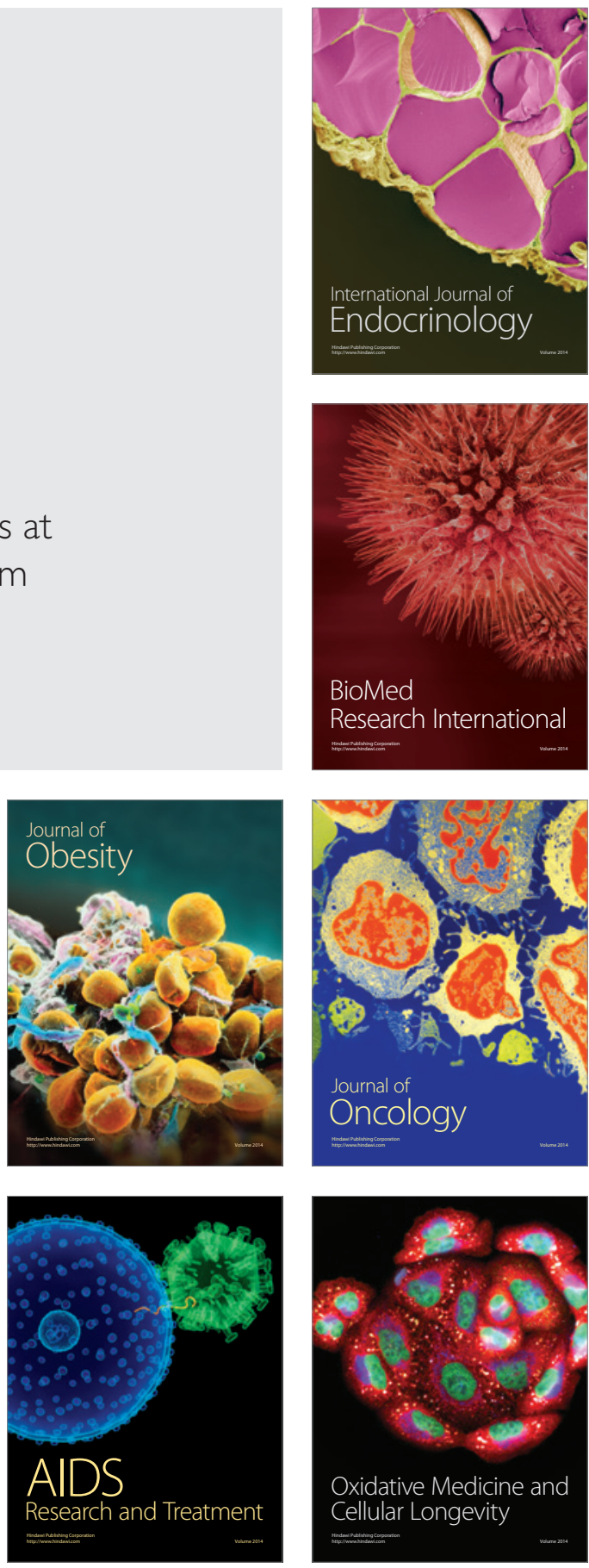